\title{
Erratum: Synthesis and Characterization of Copper Nanoparticles by Using the Exploding wire Method
}

[J. Korean Phys. Soc. 61, 710 (2012)]

Rashmita DAs, * Basanta Kumar DAs and Anurag SHYAM

Energetics and Electromagnetics Division, Bhabha Atomic Research Center, Autonagar, Visakhapatnam. A.P, India

DOI: $10.3938 /$ jkps.65.1991

Figure 2: Time scale of figure 2 was mistyped as seconds in place of microseconds. So it should be read as follows.

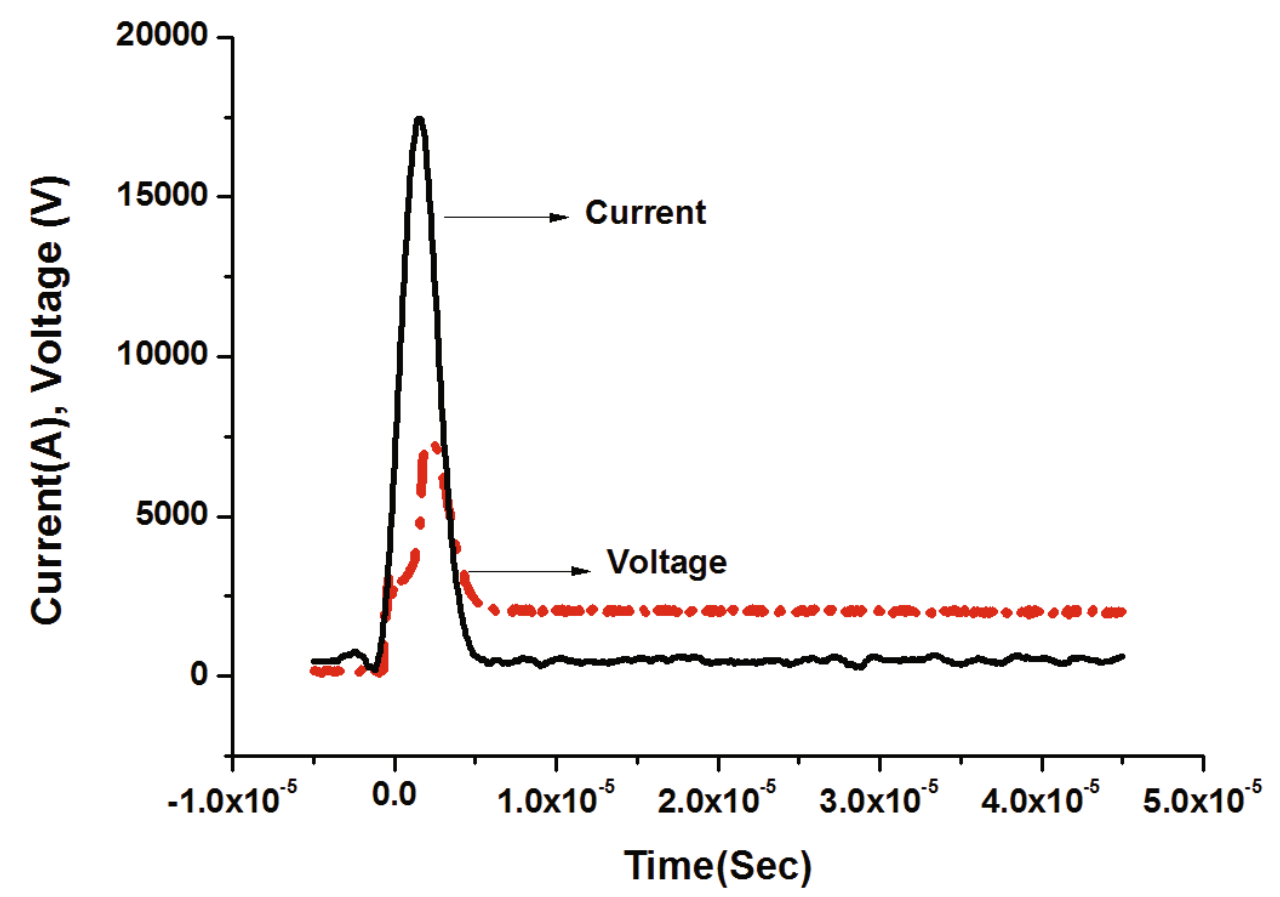

Fig. 2. (Color online) Current and voltage waveform. 